\title{
Review
}

Fetal Diagnosis

and Therapy

\section{Ethical Issues on Pregnancy Termination: Impact of New Imaging Modalities}

\author{
Guillaume Gorincour ${ }^{\mathrm{a}}$ b Sébastien Tassy ${ }^{\mathrm{a}}$ Umberto Siméoni ${ }^{\mathrm{c}}$ Pierre Le Coz ${ }^{\mathrm{a}}$ \\ ${ }^{a}$ Mediterranean Ethical Forum, EA 3783, Université de la Méditerranée, ${ }^{b}$ Multidisciplinary Center for Prenatal \\ Diagnosis, La Timone Hospital, and ' Division of Neonatology, La Conception Hospital, Marseille, France
}

\section{Key Words}

Fetus - Neonate $\cdot$ Termination of life $\cdot$ Autonomy •

Doing good $\cdot$ Doing no harm $\cdot$ Fairness $\cdot$ Transgression $\cdot$

Utilitarianism • Phenomenology $\cdot$ Empathy

\section{Abstract}

Objective: To explicate the ontological statuses of both the fetus and neonate as a basis for clinical ethical judgments about the obligations of both physicians and pregnant women to protect the life and health of both the fetus and the neonate. Methods: Despite drastic changes in perinatology, there is still a legal separation between fetuses and neonates. Neonatal status remains specific because of the prohibition of 'transgressing human life'. Nevertheless, the concept of a 'prenatal human being' recently emerged. While new technologies blur the fetus/neonate borderline, why is it still legal in many European countries to terminate a fetal life in the late stages of pregnancy? One might even support the idea that what is authorized before birth should also be after, thereby 'fetalizing' neonates. Results: The 'personalistic' approach is against this 'fetalization', considering that terminating a neonate life is 'transgressive'. The 'utilitarian' model considers we cannot decide what is good for someone else, which justifies terminating the life of neonates who are not persons yet. A phenomenological view supports the ontological difference on our perceptions, differing whether we observe ultrasound fetal images or real neonatal pictures. Conclusion: This does not mean the weight of fetal images should be underestimated.

Copyright $\odot 2011$ S. Karger AG, Basel

\section{Introduction}

With the technical progress fetal medicine has made, the separation between the fetus and neonate has become less clear-cut than it was 3 decades ago. Birth remains an important symbolical landmark, but, all the same, modern medical technology gives us data that tend to humanize the fetus, which has now become a 'patient' in its own right on equal footing with the neonate.

One might therefore wonder if it is right to continue drawing such a clear line between the status of the fetus and the neonate and, if so, on the basis of what precept. After having redeployed the main philosophical concepts of personalism and utilitarianism, we shall try and demonstrate that the ethical issues related to legitimizing neonate euthanasia interfere with our reflection on the difference in status between the 'born' and the 'unborn'. We

\section{KARGER}

Fax +4161306 1234

E-Mail karger@karger.ch

www.karger.com
(C) 2011 S. Karger AG, Basel

1015-3837/11/0301-0001\$38.00/0

Accessible online at:

www.karger.com/fdt
Dr. Guillaume Gorincour

Mediterranean Ethical Forum, EA 3783

Université de la Méditerranée, La Timone Hospital

264, rue Saint-Pierre, FR-13385 Marseille (France)

Tel. +33 49138 6797, E-Mail Guillaume.GORINCOUR@ap-hm.fr 
will privilege the modern school of thought - phenomenology - which is founded on starting out from the perceived (the 'phenomena'), deferring all forms of external interpretation. Once we have cast aside our philosophical, ideological and religious positions, we must still free ourselves from our legitimate concerns in relation to neonatal euthanasia to determine exactly where the difference that we maintain between the fetus and the neonate resides. Lastly, we shall show how the development of medical imaging and the impact of the images we can now produce are currently creating major changes in all our theoretical concepts.

Therefore, the purpose of this paper is to explicate the ontological statuses of both the fetus and the neonate as a basis for clinical ethical judgments about the obligations of physicians and pregnant women to protect the life and health of both the fetus and the neonate. Through the concept of ontological status, we understand a human being as having the capacity to be in a 'true interpersonal relationship' and therefore a 'true human being in his own right'.

\section{Role Played by the Progress in Knowledge and Technology}

Fetal medicine now has diagnostic tools (ultrasound, amniocentesis, chromosome and molecular screening, chorionic villus sampling, chordocentesis, serum markers, etc.) that reveal the development of a human being in utero [1]. The fact that technology can now show us what is going on inside the mother's body tends to humanize the fetus, making it a subject of as much attention as we give to our 'ordinary' patients. We are no longer just checking up on the health of the child that is to be born, but optimizing the way it comes into the world. When the routine surveillance of a pregnancy reveals that the fetus's well-being is compromised, in some cases we even remove it prematurely from its mother's womb to administer neonatal treatment.

The gradual awareness that the fetus is sensitive to pain [2] and the fact that there is already a life experience between the fetus and its mother are relatively recent developments, and have contributed to reducing the difference in status between fetus and neonate.

In the eyes of the law, however, the difference between the two remains quite clear [3]. So can it be that the difference between a fetus and a neonate is just related to their respective legal status? Will the formalism of the law be able to resist the ever-shrinking borderline between the two? Should we not start to think about giving the fetus the rank of 'prenatal human being' [4]?

Currently in France (and in a few other countries), medicine has the 'restricted' power to terminate the life of a fetus up until the day it is delivered if there is a strong suspicion of a serious, incurable abnormality; however, once the child is born, its life can no longer be terminated. The only legitimate way of ending its life from birth onwards is to allow it to die by withdrawing life support and administering painkillers. A lethal product can only be administered to a fetus with a very serious disorder.

This sudden ban on active euthanasia, which suddenly occurs at the moment the child is born, raises ethical issues for the neonatologists who are often faced with the fact that neonates that have been placed in intensive care on the basis of 'life at all costs' will have to live with serious sequelae. When the prognosis involves extensive disabilities, they are often left to debate with their conscience whether it would not be better to withdraw treatment, thereby allowing the child to die.

Is the neonate's sudden leap in status not exaggerated in comparison with that of the fetus it was shortly before? Public opinion is still very keenly in favor of 'allowing nature to take its course', not going against its implacable laws and abstaining from using 'aggressive or heroic therapy'. Reducing the status of a neonate to that of a fetus outside its mother's womb is in reality an approach dictated by the concerns we have regarding legitimate euthanasia for neonates whose quality of life will be very poor. This very same extrinsic concern is found in both ethical systems: personalism and utilitarianism.

\section{The Two Classical Ethical Approaches}

To understand the divergences between these two classical schools of thought, it is first important to emphasize the four universal principles that form their common base.

\section{Preliminary Considerations on the Principles of} Biomedical Ethics

A medical decision must be fair: justice is essential and it must be based on the universal principles of biomedical ethics, i.e. respecting a person's right to self-determination, doing good and doing no harm [5]. To these three mainstays of biomedical ethics that govern the relationship between physician and patient, we must add the macroethical principle of fairness. To be fair, a physician 
must include in the criteria he uses to make his decision his concern that everybody should get a fair share of the care and services provided $[6,7]$.

Although to include the full ethical dimension, the decision should include this concern for fairness, our healthcare culture is nonetheless branded by a marked reluctance to rank our scruples on how to apportion healthcare expenditure rationally on an equal footing with other principles such as doing good or respecting a person's right to decide for themselves. This is why the 'economic' issues are not as obviously part of medical decision-making in France as in some of the English-speaking countries. Our medicine is based on the 'personalistic' approach that emphasizes the importance of respecting people's right to self-determination. When a neonate has a serious neurological disorder, for example, most practitioners would find it difficult to deprive that very young child of treatment for economic reasons if the parents are adamant that they want it to survive. In such cases the neonatologists will have to sacrifice one of their fundamental values (fairness) to safeguard another that is even more important in their eyes (respecting the parents' decision).

Some might feel that the parents are perhaps not aware of how severely disabled their child will be and that it would be more compatible with the principles of doing good to spare them the torment of a life entirely devoted to looking after a severely disabled child. Biomedical ethics involve thinking about how to rank the principles in the right order when it becomes difficult to 'apply' them all simultaneously. However, how can we rank our ethical principles (the right to decide, doing good, doing no harm, being fair) when we cannot 'apply' them all at the same time?

The situation is all the more complex in neonatology because there are three parties involved in the relationship: parents, the child and caregivers [8]. The 'right to decide' principle means that the will of the parents must be respected, but the principle of 'doing no harm' pleads in favor of keeping the child alive as long as the team considers that its quality of life is not seriously compromised. This triangular relationship exists in the same way in fetal medicine: the future parents, the fetus and the caregivers.

There are two types of argument that can be used in these difficult situations: one is based on the 'transgressional' model and the other on the 'utilitarian' model. These models must be briefly described for a better understanding of the phenomenological approach.

Impact of New Imaging Modalities on

Pregnancy Termination

\section{The 'Transgressional' Model}

This is the 'classic' model used in neonatology, especially before the guidelines of the Léonetti law, which exonerates a practitioner who speeds up the demise of a patient to avoid unnecessary pain, were issued on April 25, 2005 [9]. This position defends the unconditional 'dignity' of any person, regardless of their age or physical or mental status, and is known as the 'personalistic' approach. It is for this reason that the National Ethics Committee, issued guideline No. 65 on September 14, 2000 [10], stating that neonatal euthanasia should be understood as an exception that transgresses the unconditional respect for human life. 'Transgression' means any deliberate action carried out with the intention of getting around the basic laws imposed on the community without having asked for an exception to be made to the law that embodies this ban. The underlying logic of transgression is in this respect opposed to the logic of 'normalization', which is what some of the activists in favor of the decriminalization of euthanasia advocate; they claim that everybody should have the right to determine for themselves what they mean by dignity.

The expression 'exceptional euthanasia' used by the National Ethics Committee shows their concern that these lethal practices should not be considered as normal. The idea of dignity as judged by others is not acceptable, as the judgment should be made by the person involved or by his or her legal representatives. Terminating a life does not mean denying a newborn child its dignity; it is merely the result of a series of examinations that tell us that its quality of life will be extremely poor. The concept of 'exceptional euthanasia' embodies the idea that although on the basis of doing no harm (primum non nocere) you should keep a patient alive, the principle of doing good dictates that you may have to revise your decision in regard to the resulting quality of life. In other words, the child's pain may seem worse than death, without it having forasmuch lost its dignity. It cannot just be reduced to a 'potential human being' [11] like the fetus. The decision to terminate the life of a neonate is based on an attempted evaluation of its 'potential good health, development and well-being', its 'capacity to set up relationships' and on the 'human cost for itself and the family'; in other words, the way we approach the concept of quality of life.

Seen from the personalistic approach, the difference between a fetus and a neonate is essentially connected to the fact that terminating the life of a human being can only be considered as a transgression if that person is already born. Therefore, the current law should not be 
changed but continue to authorize the termination of pregnancy for medical reasons and remain firm, maintaining the ban on terminating the life of certain neonates. Exceptional cases of transgression of the law that prohibits the termination of people's lives is an ethical issue: it is not something that can be formally written into the law and it would doubtless be dangerous to allow the decriminalization of neonatal euthanasia.

The transgressional approach runs into trouble when the issue of setting an objective threshold at which the quality of a life has become too 'poor' to be lived arises. In April 2005 [9], the French courts ruled that a person should not have the right to be assisted to die - even when in their own eyes life was no longer worth living. More precisely they should be allowed to die if they so wish and have firmly and repeatedly expressed that wish, but must not be made to die. Everybody in France remembers the death of a young man who was severely disabled as a result of a road traffic accident in 2003. The affair that later became known as the 'Vincent Humbert case' provided an opportunity for the Léonetti parliamentary commission to once again raise the issue of a major legal deadend: how can we determine the threshold at which there is no real likelihood of living a worthwhile life?

\section{The Utilitarian Model}

Some authors have proposed to blur the difference between the neonate and the fetus to get around this difficulty. For these authors, nothing, apart from the current legislation, seems to justify such a clear-cut dividing line between fetus and neonate. When we have only been alive for a few days, we don't yet have any family history or real existence. The main principle of this second school of thought is that the neonatal period is an extension of the fetal period. Those who advocate this point of view have even proposed the 'ethical unity of the fetus and the neonate' [12].

For Singer and Kuhse [13], early infanticide is no worse than late feticide. He draws a distinction between individuals who are members of the human race in the biological sense of the term and people who have awareness and reason. Some human beings are not people stricto sensu because they have no superior cognitive function. Euthanasia can thus be legitimately envisaged for severely disabled young children if it obviously ends up by 'reducing the burden of pain in our world' [14]. Singer adopts the beliefs of the utilitarian approach that states that a decision is ethically acceptable when it contributes to the happiness of the greatest possible number, or alternatively, to reducing as much pain as possible [15]. An action complies all the more with the principle of 'doing good' if the pain that it avoids is intense and the number of people spared that pain (parents, grandparents, siblings, etc.) is large.

The utilitarian model provides an answer to the main objections that can be made to the transgressional model: how can we say that a neonate's life will be of poor quality? Is there not something rather arbitrary in deciding what is right for someone else in his or her lieu and place? J.S. Mill [15], one of the founding fathers of utilitarianism, said as early as the 19th century that the utilitarian ideal does not seek the greatest happiness for the subject as such, but the greatest sum of overall happiness. In general, the parents and close relatives suffer actual, tangible pain. It is something that can be felt, recognized and anticipated by those involved, which is certainly not so for the neonate.

We can guess with great apprehension what the possible social and political abuses of the indiscriminate application of the principles of utilitarianism might lead to; it is therefore an approach that can only be used if the parties consent, which is compatible with the idea of individual freedom - one of the guiding principles of the English-speaking philosophers. Even if you think that your decision will contribute to alleviating pain, you have no right to violate the integrity of another person's body if that person has not given their consent, unless that person has deliberately harmed others: 'The only legitimate reason a community can have to use force against one of its members is to stop that person harming others. An individual has sovereign right over the integrity of his own body and mind' [16]. It is not ethically acceptable to presume that a person will consent to sacrificing his life to avoid burdening his family. As Jeremy Bentham [17], the founder of utilitarianism emphasized: 'the greatest happiness for the greatest number means weighing up what is fair and unfair', but 'the happiness of the community must be guaranteed by respecting the freedom of all'.

Thus, it is against the ethical beliefs of the utilitarian to assume that a neonate consents to the termination of his life - that is if you consider a neonate as a person. This means that neonatal euthanasia is only conceivable if the neonate's status as a 'person' is challenged to start with. If the neonate has the same ontological status as a fetus, and is thus not considered a human being, then the issue of whether he gives his assumed consent to being eliminated or not no longer arises. If the status of a neonate is no different from that of a fetus, then early forms of euthanasia can be justified on the basis of the principle that what is socially acceptable for a fetus that has reached an 
advanced stage of development should also be acceptable for another potential human being that is not physiologically any different. Why refuse on the morning of the delivery what you would have accepted on the last evening of the pregnancy [18]? If you apply this principle, it is arbitrary to accept that the life of a fetus with a serious incurable disorder should be terminated, whereas very premature babies should be kept alive at all costs, although their future prognosis is just as serious.

\section{The Phenomenological Approach}

To highlight the salient features of this position, we must first briefly sum up the main points of the two previous arguments.

The transgressional approach (personalism) recognizes that interfering with the life of a neonate is seriously wrong and should only be envisaged and considered acceptable in exceptional circumstances. It considers that terminating the life of a fetus is less serious because it is allowed in law (a legal framework can be invoked). The status of the neonate is not considered to be inferior to that of normal or older children. The administration of powerful analgesics is envisaged simply because of the probability that the child's quality of life will be very poor. The principle of doing good is used here to decrease the relevance of the principle of doing no harm.

In the utilitarian approach (consequentialism), the serious action of terminating the life of a neonate is put into perspective by aligning it with terminating a pregnancy for medical reasons. The euthanasia of a neonate is no longer seen as a 'transgression' because it becomes a simple extension of practices that are already authorized for fetuses that are affected by a serious malformation. To do this, however, it is nonetheless essential to equate the status of the neonate with that of the fetus, a potential human being: the neonate is considered as a fetus that has been taken out of its mother's womb. By proceeding in this way, we no longer have to take the risk of walking the slippery slope of assessing the neonate's future quality of life. Therefore, in the name of 'the greatest happiness for the greatest number' we can terminate the neonate's life as it is agreed that no consent is required since it has no status as a potential human being.

Does the fact that technology and medical practice are continually developing not give more weight to the arguments in favor of the utilitarian theory? The empirical data we have compiled from listening to pregnant women also argue in favor of there being no clear distinction be-

Impact of New Imaging Modalities on

Pregnancy Termination tween the two statuses. Has anyone ever heard a pregnant woman say she was 'carrying a fetus'. Is it not clear that she is already carrying a 'child'? If a woman feels as much a mother before the birth of her child as after, can we not draw the conclusion that what is acceptable for a child should also be for a fetus?

We have to recognize that the utilitarian approach has the merit of overcoming the weaknesses of transgressional personalism. However, for this we pay the price of negating the reality of what our senses perceive: the phenomenological difference that still continues to persist between a fetus and a neonate. Our concern for finding an ethical justification when we stop treating a neonate has ended up by perverting the way some of us see reality, that is to say a neonate is not exactly a fetus. This is why we really need a third approach based on the 'phenomenological theory'; phenomenology consists in keeping to the phenomena, i.e. what appears in our field of perception (in Greek 'phainomenon' means 'that which appears and is externally discernible') [19].

The answer to the question above is that once the neonate is born, it has an incarnate human face. We must consider, as Lévinas [20] does, that a face-to-face meeting with another person is a major existential event in which our ethical standards are deeply rooted. It is true that the face of a neonate is not yet the face of a child, if only because its range of expression is limited. However, these objections remain weak because a face cannot be reduced to its simple appearance. Nor can it be reduced to the parts that participate in its empirical makeup (two eyes, a nose, a mouth, a chin, etc.). The face, the body, the movements and the expression of a neonate generate a presence that elicits a relationship of empathy. Empathy means the capacity to understand the affect of others by reading the sensory information we see on their face [21, $22]$. It is because it does not have these characteristics that we have no relationship of empathy with the fetus.

Of course we respond emotionally when we see the fetus on an ultrasound examination (in particular when it is in 3 dimensions); however, the image of a fetus cannot react to its parents like a neonate can. Thus, many feel that the fetus does not strike our sensitivity as much as a neonate that we can see with our own eyes. The fetus does not fulfill the prerequisites for a true interpersonal relationship. The process of visualizing the fetus in utero just offers a technology-mediated, fleshless perception; we do not perceive a fetus, but an ultrasound morph of a fetus. Empathy can only be shared in first-degree perceptions, those that hit the senses head-on giving them body language to interpret: the position of the eyes; the contrac- 
tion of the face muscles that indicate sadness, joy, anger; etc. [23]. These prerequisites exist in neonates, but not in fetuses. One might argue that because of this, they will never have the same status.

\section{The Weight of Fetal Images}

The latter statement, however, undoubtedly denies the most recent developments in fetal medicine and the very real impact they have on the daily life of pregnant women. As a matter of fact, many studies have already studied the impact of these fetal ultrasound (FU) faces, and what really happens in clinical practice is very different from this theoretical discussion.

We saw that the ontological status of the neonate is based on its capacity for a face-to-face relationship with its parents. The neonate can initiate and respond to a relationship with its parents. The fetus cannot do this, although we will try to introduce how prospective parents can and do initiate a relationship based on fetal images when 'they meet their child', and the pregnancy becomes (more) 'real'. With normal ultrasound results, the idealized child starts to become 'real' and has increasing ontological status. If the ultrasound proves abnormal, the transition from 'idealized child' to the start of 'real child' is disrupted, resulting in decreased ontological status.

As Luc Gourand [24] says, 'The technical and legal race to keep abreast of developments, seems to us to be a reducing factor in relation to the surprising investigation tool we have and which is still considered to be notoriously under-used as an instrument to discover and develop parental skills'.

FU is a medical examination that involves several underlying paradoxes and/or ambiguities. FU is not compulsory in France (although it is covered by the health insurance scheme), but is undeniably now one of the key moments in the follow-up of a pregnancy. The goals differ according to the stakeholder: the parents' goal is to meet their future baby and make sure that it is 'normal'. The echographist is to 'hunt down' the slightest anomaly, with all the underlying medical and legal pressure this involves.

A 'normal' image will give the physician the certain pleasure of being able to reassure the parents-to-be. These are, of course, subject to the reservations inherent to the technology itself, which must be explained to the parents in terms they can understand. Although ultrasound technology has improved its performance at an exponential rate, it remains imperfect and, by definition, artificial. When using and controlling the technology, the physician's job is to strike the right balance between being excessively confident and excessively cautious. An echographist may be tempted to standardize more than necessary, although the standards are often subjective and each case is unique. As Gourand says [24, 25], 'The echographist ... walks on a razor's edge, because the implications of his interpretation are deeply rooted'.

The other extreme temptation is that any fetus can become suspect very fast and thus potentially dangerous for the physician as a possible source of a malpractice suit. This explains why the future parents so often complain that the echographists are far too obsessed by their medical goals and do not take the time to show them the fetus or offer them the opportunity to take away a video of the examination. The echographists' position is the result of a head-on clash between the diagnostic demands they are burdened with and the ever-increasing legal implications of the examination. This phenomenon has resulted in the appearance of FU 'boutiques' which are obviously not devoid of danger [26].

For the parents-to-be, a normal ultrasound examination is a privileged moment - the first time they meet their child (often the first time that the pregnancy becomes 'real' for them). The first ultrasound is in fact frequently placed in a prominent position on the first page of baby's photo album today, a pregnant mother now sees her 'baby' before she even feels it moving. This transient discrepancy between what is seen and perceived leads to a lot of fantasizing, especially when the eye falls on what Freud called 'the worrying foreignness' of the stranger inside the mother's body. If the ultrasound examination is normal, the parent's virtual child becomes real and the image is a medium that confirms and supports their expectations, maturing the parenting process; in brief, virtualizing the pregnancy on the FU is a symbolically effective rite of passage that helps them to anticipate the new baby [27]. The parents' profound desire is that there should be no contradiction between reality and this anticipated interior representation, combined, if possible, with the details that indicate that everything is alright for this 'normal' fetus to become a happy neonate.

And when an 'abnormal' image appears on the screen, the effect is like a thunderclap for all those involved. During the split second when the echographist realizes that he has found an 'anomaly' on the FU, he is immediately faced with a series of contradictory obligations. First, he must focus on confirming that the anomaly he has found 
is real and think about the complementary FU explorations he will need to do. Second, he must not show any outward reaction, because every echographist knows that the mother-to-be watches the operator's expression as much as the ultrasound screen. He also must be careful not to react too much in order to gain time to find the right words to explain the images without being too frightening or too reassuring, as we know that it is often the first words we say that remain engraved in the minds of the future parents. Thirdly, he must take on the obvious role of the bird of ill omen, the announcer of bad tidings. Then, all that he can do is turn the situation around by explaining that the diagnosis he has just made must be seen as an opportunity to do a complete series of examinations to seek the causes of the abnormality and, above all, the preferred option, which is to anticipate the intrauterine and immediate postnatal development of the fetus's condition in order to prepare for the arrival of the future baby as well as possible.

For the parents-to-be, this is the end of the idealized virtual child. When the ultrasound contradicts the idea that the future parents have (had) of their child-to-be, it induces a form of paralysis, blocking the process of virtual parenting. The ultrasound picture loses its value as a rite and no longer encourages them to 'plan ahead' [28]. According to the parents' emotional structure and the quality of the attitude and behavior of the echographist, this contradiction will have a more or less violent traumatic impact, sometimes a major one. Finally, the image will carry an even heavier burden if it is just a silent picture that they are left to interpret themselves. The echographist and his team must find 'right' words to support the parents and help them understand these images at a moment when they can come into conflict with their parenting project.

This illustrates how difficult it is to perform FU examinations in routine practice, because painful clinical situations arise frequently and must be used to stimulate our reflection and challenge ourselves constantly. As S. Missonnier emphasizes, 'the parents' awareness of the complexity (of ultrasound) is mandatory for their truly informed consent, not just as a legal safeguard but above all as a true negotiation between the parents' virtual child and our medical goals' [29]. This means that our clinical practice forces us to admit that ultrasound really does put a face on the fetus and thus dramatically complicates the phenomenological analysis of the setting. The time is perhaps right for a (public?) debate on the necessary evolution of the status of the fetus.

Impact of New Imaging Modalities on

Pregnancy Termination

\section{Conclusion}

Our current reflection on the respective status of the fetus and the neonate is often biased by our practical concern to justify the decision to terminate the life of one or the other. Since the personalistic theory a priori gives the neonate the status of a 'human being', we must conclude that any decision to terminate the life of a neonate can only be euthanasia and thus a 'transgression'. However, this must be opposed to the utilitarian objection that in the strictest sense of the term, euthanasia must be understood as something that can only be claimed by a subject capable of indicating the degree of well-being and quality of life that is acceptable to him. This is why utilitarianism prefers to negate the neonate's status as a true human being in his own right, thereby considering that withdrawing life support and allowing it to die is the ultimate form of termination of a future human life.

Because these two philosophies embody the concerns related to how a decision involving terminating a life can be justified, they do not really address the issue of the ontological status of the fetus and the neonate. They both consider that certain pre- or postnatal practices are necessary and draw the appropriate conclusions concerning the status of the beings concerned. However, the status of a being cannot depend on the way we deal with it.

To answer the ontological issue of 'How should we rank fetuses and neonate as human beings?', we need to use the phenomenological approach, which is based on leaving aside the issue of euthanasia and describing what we truly see, as we see it, without any mental reservations. This standpoint suggests that the decisive factor is the impact of the human face.

As a human being with a face, the neonate carries a higher ontological value than the fetus and should be ranked on an equal footing with any other person. This is why it is difficult to put the gravity of infanticide into perspective by aligning it on feticide. The phenomenological approach suggests that terminating the life of a neonate escalates one degree higher than terminating the life of a fetus on our scale of values. Birth remains the event that justifies the change of status from fetus to neonate because it is the first time that the child's face truly appears before our eyes. The emerging issue is that the fetal faces we see on our FU scans will become more 'emotionally' and phenomenologically loaded as time goes by.

But although phenomenology is inclined to approve the idea that all neonates are people, even those who are seriously ill, one cannot agree without any reservations with the personalistic theory of transgression. The utili-

Fetal Diagn Ther 2011;30:1-8 
tarian objection that consists in saying it is not acceptable to make decisions regarding the well-being and the quality of life of a human being that has not given his own opinion on the issue is to be taken seriously. So rather than using the word 'euthanasia', perhaps it would be more suitable to talk about terminal care, withdrawal of treatment and refusing unreasonable obstinacy, in compliance with the Léonetti act. In fact, some fetal medicine centers are now offering postnatal terminal care as an alternative to late termination of pregnancy.

The phenomenological description of the break-off point between fetus and neonate can no longer be as marked as it has been in the past as a result of the progress in fetal medicine (ultrasound) and neonatal care (extremely premature neonates) [30]. If the fetus were to be given a legal status - elevated to the rank of a 'prenatal human being' - this might well pose as many, if not more, issues than it would resolve. It is nonetheless true that the protection of the fetus must be adapted to the progress we have made in perinatal care [31].

\section{Disclosure Statement}

All authors have declared that they have no conflict of interests that may be relevant to the submitted work.

\section{References}

1 Rappaport VJ: Prenatal diagnosis and genetic screening - integration into prenatal care. Obstet Gynecol Clin North Am 2008;35: 435-458, ix.

$>2$ Lee SJ, Ralston HJ, Drey EA, Partridge JC, Rosen MA: Fetal pain: a systematic multidisciplinary review of the evidence. JAMA 2005;294:947-945.

3 Copelon R, Zampas C, Brusie E, Devore J: Human rights begin at birth: international law and the claim of fetal rights. Reprod Health Matters 2005;13:120-129.

4 Sureau C: Son nom est personne. Paris, Albin Michel, 2005

5 Beauchamp TL, Childress J: Principles of Biomedical Ethics, ed 5. Oxford, Oxford University Press, 2001.

6 Elster J, Herpin N (eds): 'The Ethics of Medical Choice'; in The Ethics of Medical Choice. Social Change in Western Europe. London, Pinter/St. Martin's Press, 1994.

7 Gatherer A: Ethics and medical decisionmaking. Family Practice 2003;20:223-a.

8 Stringer M, Shaw VD, Savani RC: Comfort care of neonates at the end of life. Neonatal Netw 2004;23:41-46.

9 Official Journal of the French Republic. 2005. Loi No 2005-370 du 22 avril 2005. Journal Officiel No 95.

10 National Ethics Committee. Réflexions éthiques autour de la réanimation néonatale, avis No 65. 2000. http://www.ccne-ethique. fr.
11 National Ethics Committee. Avis sur les prélèvements de tissus d'embryons et de fœetus humains morts, à des fins thérapeutiques, diagnostiques et scientifiques, avis No 1. 1984. http://www.ccne-ethique.fr.

12 Gold F, Laugier J: Decision about stopping therapy in neonatal intensive care units. Taking the initiative in the management of handicaps. Arch Fr Pediatr 1992;49:5-7.

13 Singer P, Kuhse H: Should the Baby Live? Oxford, University Press Oxford, 1994.

14 Singer P: Voluntary euthanasia: a utilitarian perspective. Bioethics 2003;17:526-541.

15 Mill JS: L'utilitarisme. Paris, Champs Flammarion, 1988.

16 Mill JS: On Liberty and Others Essays: Oxford World's Classics. New York, Oxford University Press, 1991.

17 Bentham J: Guaranties against Abuse of Power and Other Writings on Political Liberty. Paris, Editions Rue d'Ulm, 2001.

18 Niessen F, Vial M, Magny JF, Dauphin F: Les seuils de développement de l'être humain et la décision éthique dans la pratique obstétrico-pédiatrique. Reprod Hum Horm 1997; 10: 66-78.

19 Husserl E: Leçons pour une phénoménologie de la conscience intime du temps: coll 'Epiméthée'. Paris, PUF, 1996, section II.

20 Lévinas E: Ethique et infini. Paris, Livre de Poche, 1984.

21 Griffiths PE: What Emotions Really Are. Chicago, University of Chicago Press, 1997.

22 Loewenstein G, Lerner JS: The role of affect in decision making; in Davidson RJ, Goldsmith HH, Scherer KR (eds): Handbook of Affective Science. Oxford, Oxford University Press, 2003.
23 Baron-Cohen S, Tager-Flusberg H, Cohen DJ: Understanding Other Minds, Perspectives from Autism. New York, Oxford University Press, 1993

24 Gourand L: L'échographiste et l'accès au ventre. Rev Fr Psychosom 2004;26:71-83.

25 Lenhardt F, Gourand L: Echography and prenatal diagnosis (in French). Soins Gynecol Obstet Pueric Pediatr 1993;147-148:2933.

26 Gorincour G, Tassy S, Le Coz P: The moving face of the fetus - the changing face of medicine. Ultrasound Obstet Gynecol 2006;28: 979-980.

27 Missonnier S: L'enfant virtuel et les jeux échographiques, Champ Psychosomatique 2006;43:37-53.

28 Maisonneuve J: Les conduites rituelles. Paris, PUF, 1988.

29 Missonnier S: Entre extrême incertitude et extrême onction: le diagnostic fotal. Champ Psychosomatique 2005;45:71-84.

30 National Ethics Committee. A propos de la conservation des corps des fotus et enfants mort-nés, Réponse à la saisine du Premier Ministre, avis No 89. 2005. http://www.ccneethique.fr.

31 Dageville C, Rameix S, Andrini P, Betrémieux P, Jarreau PH, Kuhn P, Oriot D: End of life in neonatal medicine in the light of French law. Gynecol Obstet Fertil 2008;36: 571-581. 